\title{
Mentoria em programação: aprendendo ao ensinar e ensinando ao aprender
}

\author{
Thais Regina de M. B. Silva ${ }^{1}$, Gláucia Braga e Silva ${ }^{1}$, Maria Theresa Arruda Henriques ${ }^{1}$ \\ ${ }^{1}$ Instituto de Ciências Exatas e Tecnológicas \\ Universidade Federal de Viçosa (UFV) - campus Florestal \\ \{thais.braga, glaucia, maria.theresa\}@ufv.br
}

\begin{abstract}
Several papers from literature show the regular difficulties faced by students when they start their computer programming learning process. Particularly, this issue can raise girls' resistance and evasion rate. This work presents how mentoring relationships instituted in the MinasCoders program lead to an increase of interest in programming, its related courses and in the technological area in general. The results show that mentor empowerment and mentored belonging feelings can be transformed into concrete technical learning.
\end{abstract}

Resumo. Diversos trabalhos na literatura mostram as dificuldades rotineiras encontradas por estudantes no processo inicial de aprendizado da programação de computadores. Em particular, esta questão tem o potencial de aumentar a resistência e a evasão de meninas. Este artigo apresenta a forma como relações de mentoria foram instituídas no programa MinasCoders, despertando interesse e motivação na programação, nos cursos e na área de tecnologia de modo geral. Os resultados mostraram que o empoderamento de mentoras e o sentimento de acolhimento de mentoradas se traduziram em aprendizado concreto.

\section{Introdução}

O aprendizado da programação de computadores é um dos requisitos básicos com o qual discentes de cursos de nível técnico e superior ligados à Tecnologia da Informação (TI) precisam lidar. Entretanto, diversos trabalhos científicos têm atestado falta de sucesso no processo de ensino/aprendizado da programação introdutória, manifestada pelos altos índices de reprovação em disciplinas de base e de evasão de alunos. O trabalho em [Medeiros et al. 2020] apresenta uma série de habilidades e desafios ligados ao ensino/aprendizagem de programação, recolhidos na compilação de 69 artigos em português publicados entre os anos de 2010 e 2016. Já os autores em [Arimoto and Oliveira 2019] aplicaram, entre os anos de 2017 e 2018, um questionário com 38 perguntas a 284 alunos de cursos técnicos e superiores da área de computação, com o objetivo de identificar dificuldades no processo de aprendizagem em programação. Em ambos os casos o uso de métodos e ferramentas inovadores foi destacado como ação capaz de mitigar problemas.

Os trabalhos mencionados acima não fazem distinção quanto ao recorte de gênero. Porém, dados aspectos históricos que excluiram mulheres da TI, a falta de melhores abordagens no ensino de programação pode ser especialmente impactante para este grupo. Uma variedade de artigos da literatura discutem estratégias centradas na criação e fortalecimento de comunidades de apoio como forma de melhorar o processo de ensino e aprendizagem de programação para este segmento. Em [Pinto et al. 2020], os autores 
apresentam um relato sobre a aplicação de atividades de computação plugada e desplugada no contexto de uma gincana promovida por alunas de nível superior para meninas do ensino médio. O trabalho de [Flôr et al. 2020] descreve as ações desenvolvidas por um projeto responsável pela criação de uma rede de estímulo à participação e formação de meninas e mulheres em carreiras ligadas à TI. Já em [Bordin et al. 2020], as autoras apresentam uma iniciativa de tutoria entre docentes e discentes dos cursos de ciência da computação e engenharia de software de uma Instituição de Ensino Superior.

O objetivo geral deste trabalho é apresentar o uso de relações de mentoria estabelecidas entre mulheres em diferentes estágios de estudo e trabalho no contexto do programa MinasCoders ${ }^{1}$, como uma alternativa eficaz para impulsionar seus processos de aprendizagem de programação. A seguir, no artigo, serão apresentadas as formas como essas relações foram fomentadas, bem como alguns dos resultados obtidos tanto para mentoras como para mentoradas ao longo do período de 2017 a 2020.

\section{Meninas conectadas para ensinar e para aprender programação}

Desde 2017, o programa MinasCoders tem realizado ações para atrair, motivar e fixar meninas da comunidade de Florestal/MG nos cursos de informática e computação da Universidade Federal de Viçosa - campus Florestal. A principal abordagem tem sido fomentar a criação de uma comunidade de meninas ${ }^{2}$, de diferentes estágios de estudo, que promova um espaço seguro, confortável e motivador para a prática da programação. Para isso, se estabelece, de forma contínua e periódica, entre as meninas da comunidade um processo de transmissão de conhecimento e de apoio social, emocional e técnico, conhecido como mentoria, com o intuito de proporcionar, para aquelas que atuam como mentoras, uma oportunidade de consolidarem e ampliarem seus conhecimentos em programação e para as mentoradas, um espaço supervisionado para treinamento e prática da programação.

Considerando a diversidade de interesses, estágios de estudo e conhecimentos em programação, em 2020, a comunidade foi reorganizada em 4 subgrupos temáticos: BOTztreinamentos para maratonas de programação; FullStackMinas - estudos sobre tecnologias do mercado, com aplicação em desenvolvimento de projetos; Codelour@s: acolhimento de calour@s e apoio ao ensino da programação; e TechnovationMC: treinamento de meninas do ensino médio/técnico para competições de tecnologia e empreendedorismo. Embora esses subgrupos estejam todos ligados ao ensino e ao aprendizado em programação, eles usam estratégias distintas para fazê-lo.

\subsection{As relações de mentoria no contexto dos subgrupos}

De acordo com o contexto de cada um dos subgrupos, o ensino e o aprendizado em programação vai se construíndo, por meio de relações de mentoria entre alunas dispostas a ensinar (mentoras) e aquelas que querem aprender (mentoradas). Em geral, as mentoras atuam também como líderes dos subgrupos, sendo responsáveis por tarefas de recrutamento, coordenação dos encontros semanais ${ }^{3}$ para estudos e treinamentos (mão na massa) e dinâmicas motivacionais para manterem o subgrupo unido. As relações de mentoria são divididas em duas categorias: mentoria sênior, para os Subgrupos BOTz, FullStackMinas e Codelour@s; e mentoria júnior, para o Subgrupo TechnovationMC.

\footnotetext{
${ }^{1}$ Programa de extensão universitária MinasCoders - https://minascoders.caf.ufv.br/

${ }^{2}$ Meninos participam da comunidade em número menor ou igual ao das garotas.

${ }^{3}$ Os encontros passaram a ocorrer de forma remota devido à pandemia da COVID-19.
} 
A categoria sênior abrange relações de mentoria entre alunas do bacharelado em Ciência da Computação, alunas de pós-graduação, nível mestrado, e profissionais do mercado. Para o $B O T z$, que abrange o estudo de programação competitiva, alunas que estão em períodos mais avançados do curso e/ou que tenham maior afinidade e facilidade com a programação atuam como mentoras de seus pares, produzindo material de apoio, organizando o subgrupo em times, selecionando exercícios avançados aplicados em edições anteriores das competições, promovendo competições internas e dando um suporte técnico de tira dúvidas e correção de bugs dos códigos produzidos pelos times. Nesse subgrupo, participam também da rede de mentoria egressas do curso, que estejam cursando pós-graduação (mestrado), e que possam fazer participações pontuais na comunidade, sendo, por exemplo, coach dos times nas competições. Já o FullStackMinas, focado no estudo de programação de forma mais aplicada, com uso de tecnologias que estejam sendo amplamente praticadas no mercado, as relações de mentoria se estabelecem em duas camadas: uma interna entre os próprios alunos do subgrupo e outra externa, em que profissionais oriundas de empresas parceiras do MinasCoders apoiam o trabalho da líder/mentora. Para isso, o subgrupo é organizado em equipes que elegem seus representantes para receberem minicursos e treinamentos em uma determinada tecnologia, promovidos pelas profissionais de mercado. Cada representante atuará com mentor de sua equipe, repassando os conhecimentos adquiridos para sua equipe para que juntos eles possam aplicá-los no desenvolvimento de um projeto em um dado contexto fictício. Por fim, o Codelour@s objetiva apoiar o aprendizado em programação das calouras do curso de Ciência da Computação. Para isso, alunas de períodos mais avançados, atuando como líderes e mentoras do subgrupo, produzem apostilas com fundamentos básicos de programação, propõem exercícios práticos de treinamento, esclarecem dúvidas e ainda realizam um trabalho de acolhimento e aproximação com as calouras.

A categoria de mentoria Júnior, por sua vez, ocorre no contexto do TechnovationMC, que desde 2018 tem fomentado a participação de meninas do ensino médio/técnico na competição Technovation Girls (TG) ${ }^{4}$. Nesse subgrupo, as meninas são mentoradas por alunas do bacharelado em Ciência da Computação e também por alunas do curso Técnico em Informática que já tenham participado da competição em anos anteriores, mas que por restrições de idade já não possam mais participar. As meninas mentoradas são organizadas em equipes e recebem, semanalmente, treinamentos técnicos sobre negócio, marketing e desenvolvimento de aplicativos para que possam propor e desenvolver um aplicativo que resolva um problema do mundo real. Guiadas pelo material de referência disponível na plataforma da competição, as mentoras produzem apostilas, videoaulas, minicursos e demais conteúdos que apoiem as equipes na produção dos entregáveis requeridos. A atuação das mentoras também abrange o apoio motivacional para que as equipes consigam concluir suas participações na competição, se sintam empoderadas e, principalmente, motivadas a permanecerem na área de TI.

\subsection{A experiência na visão de mentoras e mentoradas}

As meninas da comunidade foram convidadas a responderem um questionário de avaliação da percepção das mesmas quanto ao impacto da experiência de mentoria para seu aprendizado em programação. O questionário abrangeu 15 perguntas, sendo 14 delas fechadas (elaboradas em escala Likert e variando de "Extremamente Importante" para

\footnotetext{
${ }^{4}$ https://www.technovationbrasil.org/
} 
"Nada Importante") e 1 questão aberta, em que as meninas puderam falar sobre a influência de sua participação na comunidade em termos de aprendizado e motivação para estudar programação. Os gráficos das Figuras 1 e 2 apresentam os resultados quantitativos obtidos entre as 18 meninas do programa, sendo 9 delas pertencentes ao grupo de mentoras e as outras 9 ao grupo de mentoradas. Já a Figura 3 traz duas nuvens de palavras construídas a partir das respostas de mentoras e mentoradas para a questão aberta.

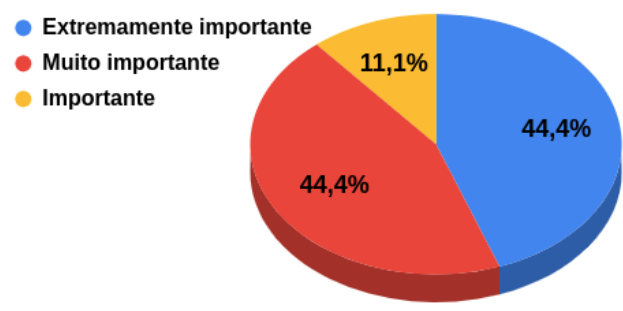

(a) Motivação Mentoras

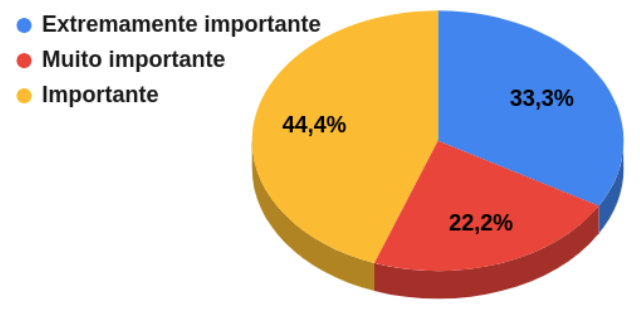

(b) Motivação Mentoradas

Figura 1. Avaliação positiva na motivação para estudar programação

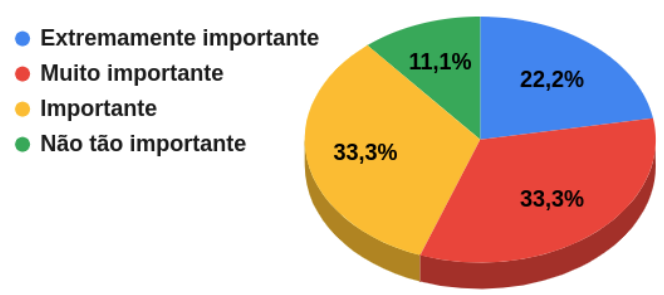

(a) Importância Mentoras

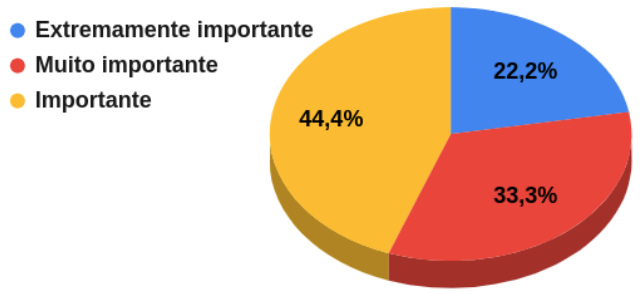

(b) Importância Mentoradas

Figura 2. Impacto positivo na importância do aprendizado em programação

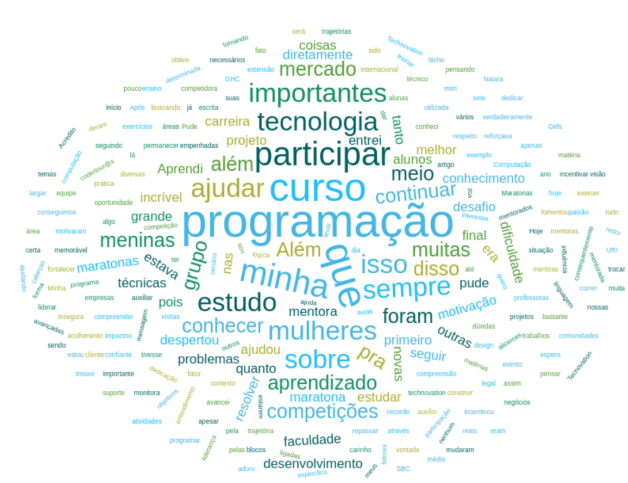

(a) Percepções do ponto de vista das mentoras

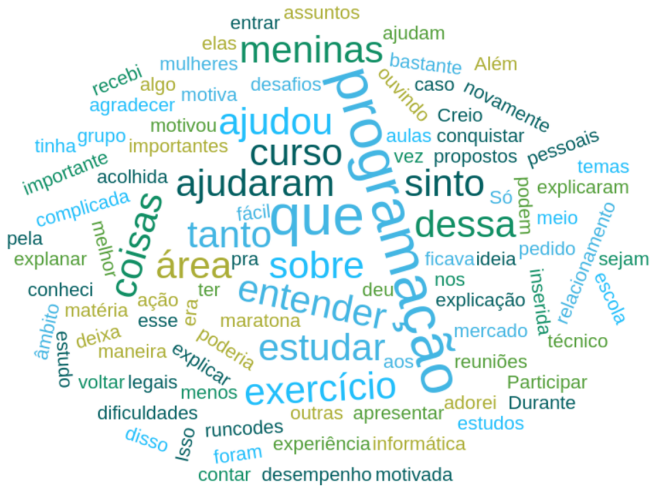

(b) Percepções do ponto de vista das mentoradas

\section{Figura 3. Termos sobre motivação, empoderamento e impacto na formação}

Segundo os resultados (Figuras 1 e 2), observa-se que a participação na comunidade tem um impacto ainda maior para as mentoras, já que $88 \%$ avaliaram como "Extremamente Importante" ou "Muito Importante" a experiência em termos da motivação para estudar programação e, para mais da metade delas (55.5\%), a experiência também 
é muito positiva ("Extremamente Importante" ou "Muito Importante") em termos de importância para o seu aprendizado na área. Também observa-se o impacto positivo para as mentoradas, já que mais da metade delas $(55.5 \%)$ avaliou como "Extremamente Importante" ou "Muito Importante" a experiência tanto em termos de motivação para estudar programação quanto no que diz respeito à importância para seu aprendizado na área. Por fim, as nuvens de palavras (Figura 3) construídas a partir das respostas da questão aberta destacam os ganhos obtidos tanto na perspectiva de quem ensina quanto na de quem aprende. Observa-se que as mentoras parecem estar mais empoderadas e competitivas como programadoras, mais maduras em relação ao curso e conscientes da importância de sua representatividade no mercado de trabalho (termos em destaque: "programação", "curso", "competições", "mulheres", "tecnologia"). Já as mentoradas parecem se sentir acolhidas e amparadas, reconhecem o suporte das mentoras e parecem ter superado algumas dificuldades quanto ao aprendizado em programação (termos em destaque: "programação", "estudar”, "ajudaram”, "entender", "curso”, “sinto”).

\section{Considerações finais}

Este trabalho abordou o uso de relações de mentoria no âmbito do programa MinasCoders como forma de promover o estudo de programação. Os resultados apontam para um vínculo concreto entre mentoria e aprendizado, manifestado em melhores níveis de aprovação em disciplinas (e.g., alunas do MinasCoders ingressantes em 2020 tiveram $71 \%$ de aprovação na disciplina introdutória de programação) e de motivação para seguirem em frente (nesta mesma turma, houve apenas $12 \%$ de desistência). O trabalho prosseguirá com a obtenção e análise de dados quantitativos e qualitativos segmentados por diferentes recortes, tais como subgrupos e tempo de participação no programa. Agradecemos aos nossos parceiros: UFV, FAPEMIG, DTI Digital e ACA Sistemas.

\section{Referências}

Arimoto, M. and Oliveira, W. (2019). Dificuldades no processo de aprendizagem de programação de computadores: um survey com estudantes de cursos da Ârea de computação. In Anais do XXVII Workshop sobre Educação em Computação, pages 244-254.

Bordin, A., Finger, A., Gindri, L., and de Mello, A. (2020). Tutoria das gurias: Uma ação de acompanhamento de alunas ingressantes em cursos de computação. In Anais do XIV Women in Information Technology, pages 129-138.

Flôr, D., da Cruz, E., Possebom, A., Junior, C. B., Hübner, R., Gonçalves, P., da Silva, C., and Aylon, L. (2020). Mannaacademy: impulsionando o protagonismo feminino através de uma rede interinstitucional de extensão universitária. In Anais do XXVIII Workshop sobre Educação em Computação, pages 26-30.

Medeiros, R., Falcao, T., and Ramalho, G. (2020). Ensino e aprendizagem de introducao a programacao no ensino superior brasileiro: Revisao sistematica da literatura. In Anais do XXVIII Workshop sobre Educação em Computação, pages 186-190.

Pinto, N., Araujo, A., Mendes, E., Pavani, G., Silva, K., Neto, R., Salles, K., and Rivero, L. (2020). Quando a aluna se torna a mestre: Um relato da experiência de alunas de graduação aplicando dinâmicas de ensino de computação para alunas de ensino médio. In Anais do XXVIII Workshop sobre Educação em Computação, pages 36-40. 